\title{
Accelerated Technology Adoption by Consumers During the COVID-19 Pandemic
}

\author{
Rouxelle de Villiers* \\ Auckland University of Technology (AUT), New Zealand
}

*Corresponding author: Rouxelle de Villiers, Faculty of Business and Law, Department of Marketing, Auckland University of Technology (AUT), Auckland New Zealand.

Received Date: August 24, 2020

Published Date: September 09, 2020

\begin{abstract}
Crisis-driven accelerated technology adoption (CATA) resulting from the COVID-19 pandemic requires marketers and retailers to revisit the marketing playbook and adjust strategies to accommodate rapid changes. From a case-based analysis of three industries, a model of six customercentric and three internal-facing corporate strategies can be derived. This new CATA model can assist manufacturers and retailers to consider strategies and tactics to artificially improve or accelerate the adoption of inventions and innovations by the majority of consumers, before competitors achieve a foothold or can enter the marketplace with their own alternatives, allowing first move advantage for a longer time or a higher share of market. The model provides an agenda for future research into CATA.

Crisis-driven accelerated technology adoption (CATA) resulting from the COVID-19 pandemic requires marketers and retailers to revisit the marketing playbook and adjust strategies to accommodate rapid changes. A speedy story: Before COVID-19, my 84-year old mother swore never to have a mobile phone and added "if you want to talk to me, phone me... if you want to see me, come visit me". As soon as lockdowns and travel bans were put in place, she bought a top-end mobile device and now estimates she spends "half her day" on Zoom, on WhatsApp or browsing the internet. How did this major mind-shift happen? CATA!
\end{abstract}

Keywords: Consumer decision-making; Imitators, Innovators; Insteads; Inventors

\section{Introduction}

The COVID-19 pandemic [1] has accelerated technology adoption by constraining the satisfaction of consumer needs and forcing adoption or creative adaptation of new technologies to meet those needs. As consumers adjust to the new constraints, so must marketers. This short review article examines three examples (online shopping for housing, online classes for teaching/learning and video conferencing) in a framework of nine strategies (six consumer-facing and three internal-facing corporate strategies) to parse out lessons and suggest possible marketing opportunities. Textile manufacturers and retail marketers likely ask: what can we learn from this global pandemic's influence on consumers' technology adoption that we might use to stimulate faster, more effective technology or new product adoption? (Figure 1).

The classic Bass Diffusion Model [2] (Bass, 1969; 1987) assumes each market has a fixed population, $\mathrm{M}$, of potential customers, split into Innovators and Imitators. During a crisis such as COVID-19 pandemic (C19), $M$ increases in size due to the crisis-nudged arrival of a new consumer segment we label the "Insteads". Before the crisis, these customers were consumers of other products/ services which met their needs (or were non-consumers), but the crisis constrained their need satisfaction and required them to try something new - instead. Where Innovators are stereotypically focused on product features/uniqueness, and Imitators are focused on following influencers, the Insteads segment is basic needsdriven (safety, security, survival, social inclusion) and these newly elevated needs, drive demand, not only bringing adopters, early, late majority and laggards [3] forward into the market earlier, but also adding new entrants (the Insteads) to the marketplace -thus increasing the size of the market. We examine the nuances of this orientation across nine different strategies below. 


\section{Consumer-Facing Strategies (Insteads-Orientation)}

\section{High levels of general product solution awareness, combined with push/pull influences}

The pace of technology acceptance is speeding up [4]. With more people of a wider range of generations being socially connected via various internet-based technologies, adoption is likely to speed up even further. Hyper-competition will keep increasing, but products that solve customers' problems better than the competition, will still win out. Raising awareness of and certainty about how one's products solve problems for all stakeholders (all along the supply chain), is still key to achieve acceptance and trail - cutting through the noise, opportunities and threats raised by competitors. Zoom ${ }^{\mathrm{TM}}$ reports [5]) that, for raising awareness traditional (even old school marketing) like print advertisements, billboards, sponsorships and mass marketing in combination with digital eWOM and product endorsements will play a role. But, combined with that, in an integrated marketing communication effort, Zoom and various educational providers take a top-down and bottoms-up combined push-pull approach. This means that marketers find large influential groups (e.g., Zoom signed up the top 200 universities to use Zoom for conference class [5]) AND advertised to students and private individuals. Marketers do well to find corporate clients to adopt their technology, enabling employees to act as advocates and highly engaged co-creators of improvements. An example for textiles might be introducing branded apparel to a large corporate (e.g. propose Allbird shoes to a retailer as uniform and allow staff to share in the opportunity of marketing them to family and friends. Incentivizing retail staff to provide co-created social media coverage - make them your best marketers) [6]. Help to build the reputation and credentials of the entire industry, and then build your brand to make you the preferred provider in a highly regarded industry.

\section{Customer satisfaction (still) comes first}

Until very recently Zoom was just a brand/word conference geeks and technology enthusiasts would know [7]. But today, in C19-lockdown, Zoom is just like Google and Uber, a verb. First time installations of the Zoom App skyrocketed by $728 \%$ since 2 March 2020 - a brief period of 5 months. Total earnings year-over-year has increased by $86 \%$ over a one-year period [8]. The primary reason CEO Yuan cites for this tremendous growth: "That focus has continued to guide all our innovations, partnerships, and other initiatives. The fantastic growth we're experiencing and the many industry accolades we've received can all be attributed to having satisfied customers that enjoy using our platform."... "We have a relentless focus on making the best product with the best user experience. This is ultimately what every customer wants. Toward this end, we spend much of our time listening to customers and fine-tuning our software to fit their needs" [7]. These words are echoed by Google's VP Marissa Mayer [9] "I used to call this 'Users, Not Money.' We believe that if we focus on the users, the money will come. In a truly virtual business, if you're successful, you'll be working at something that's so necessary people will pay for it in subscription form. Or you'll have so many users that advertisers will pay to sponsor the site." Focusing on how the technology innovation which solve problems for a variety of users better than anything else available, that are still the primary keys to early adoption and market dominance.

\section{The importance of being social}

The fashion industry knows better than most industries how to create a fad: a quick uptake of a new style by a concentrated niche market, with possibly as quick a loss of interest and decline in interest $[10,11]$. Unlike a fad with its short-lived adoption-decline cycle, studies indicate that C19 uptake of Zoom and online property purchases (via Zillow [12]) have not only been quick but captured a very large percentage of market share. An avoid/approach strategy might lead to this success. C19 nudged consumers to deliberately avoid the risks of being out of touch and risk becoming ineffective in their social and professional circles - they need to physically isolate, but socially connect and stay close. Further, consumers (perhaps more prevalent in luddites) needed to overcome their physical, psychological, financial and social fears of the new technology to gain important personal safety, social and self-actualization benefits. Thus, an important lesson from the C19 playbook for retailers and textile innovators is to consider how to position their invention to address personal and social sub-grouping needs over the full hierarchy of needs - from individual survival, personal safety and security, group social benefits and self-actualization needs simultaneously. A question innovator might ask to capitalize on this trend is how can we add a social safety and sense-of-community element to our innovation or at least to the early consumer decision or problem recognition stages?

\section{The importance of being earnest:-trust}

Moore describes the innovation adoption "chasm" and predicted delays in technology adoption laggards (luddites) and the late majority of consumers $[13,14]$. It is noticeable that during the C19 lockdown, not only did the chasm disappear for Zoom and the property industry (see ZILLOW), but adoption by the early and late majority of consumers were rushed forward, to achieve market penetration and huge market share capture much quicker and much more effectively than for competing providers. Moore [14,15] suggested that influencers and compatibility (to consumers' current lifestyle, buying behaviour and needs) will bridge the chasm. This review confirms that tools widely adopted by consumers' influencers (children, colleagues, friends and social circle) during the C19 pandemic, provided people with the impetus to adopt new buying habits (through digital channels) they might not have considered otherwise. For example, Zillow reports [12] that, in sharp contrast to the anticipated drop in property sales during C19 lockdown, "digital tools widely adopted during the coronavirus pandemic are giving people the ability and the confidence to buy or sell a home in a tight real estate market where homes are selling 
at their fastest pace in two years". The Zillow® survey [12] finds consumer demand will likely keep those tools in place and lead to more online real estate transactions in the future. Consumers are likely to accept new technology to provide them with some level of guarantee of protection against fraud and other forms of personal discomfort or hazard. So, marketers will do well to spend limited resources liberally on delivering the brand promise and then... consistently DELIVER! Make it easy to get the service. Make it easy to get sorted. Make it easy to complain. Make it easier stakeholder across the entire supply chain and for consumers along then entire customer journey, to trust role players. Make it easier to (and incentivize reviews and brand comments) provide feedback and for prospects to find existing, helpful, balanced customers' reviews $[16,17]$ (See Figure 2).

\section{New adopters}

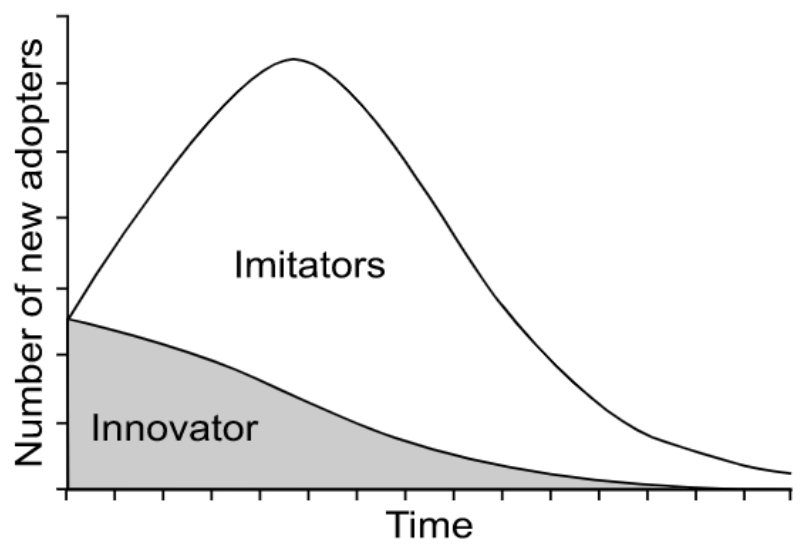

Figure 1: Crisis-driven accelerated adoption by "Insteads".

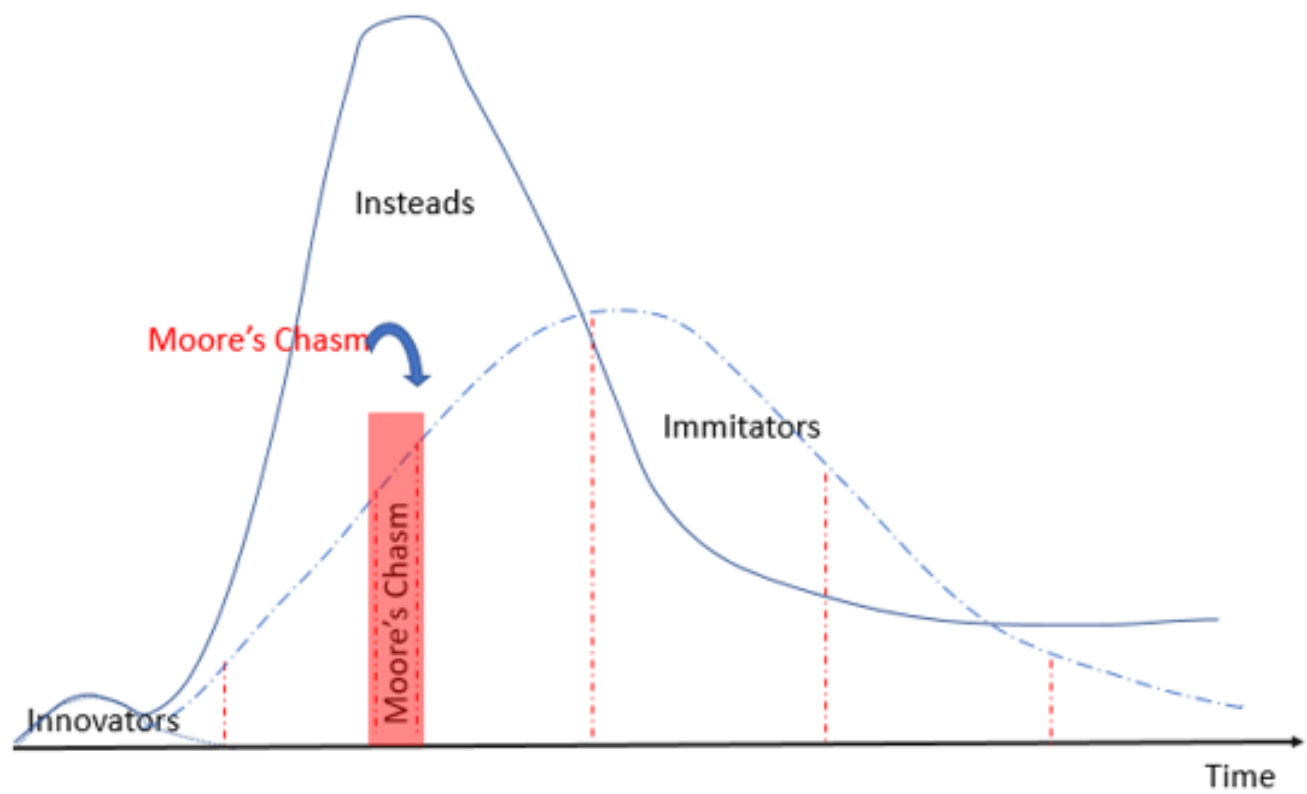

Figure 2: Accelerated Adoption and Market Size Increase by Insteads.

\section{Intermediated experiences \& joint non-competitive ventures}

It has long been known that the reliability and quality (including their social responsibility) of the entire supply chain is important to innovators and inventors. The successful shift into cyberspace of service provision, retail online browsing (viewing products) and all five stages of the buying cycle, has been mediated by various providers such as Uber (for food and cars), Amazon (for books and other products), Zoom (for conference calls and education) and various payment methods such as PayPal and bitcoin. Timelines 
for radically shortened adoption cycles depend on the selection of that can bring the service right to the fingertips and doorsteps of consumers. The choice of partner is critical to the adoption process. Although radical and disruptive innovation are likely to be scary to the masses (as too many "new" steps in the process are likely to scare the majority away), using trusted allies and non-competing reputational alliances to interface with consumers will allow newcomers and prospective buyers to negate the fears mentioned earlier. The choice of channels and partners over the entire customer journey - from initial problem recognition to the post-purchase decisions to remain loyal, recommend or discard.

During C19 lockdown consumers (even luddites) shifted almost instantly to the convenience and personal security (social distancing) offered by digital channels for communication and online portals for shopping and socializing. Vast increases in WhatsApp correspondence, Zoom-facilitated meetings, online shopping and digital classrooms are to name but a few of the almost overnight adoption of technologies by luddites. Innovators cannot control the contextual factors such as global health threats (or can they?) but marketers can identify fears and foes that can be harnessed to add weight to the benefits sought. Further, choosing familiar allies with solid track records during the launch phase and to persuade laggards to join users, may be an important part of the strategy to overcome inertia and buyer resistance. Further, from the lesson book of Zoom, constantly seeking and building consumer feedback into the development stages will result in valuable solutions that consumers trust. Zillow reported that "home buying, selling and financing platforms are leveraging emerging technologies to immerse browsers in the space of a potential home, boosting shopper confidence during the selection process as well as empowering consumers to experience locations safely, on their own terms."

\section{Co-creation \& consumer control}

Research from the US reports that $80 \%$ of property buyers and sellers would change to work with an agent providing immersive 3D-property touring, self-touring and remote buying options. Potential buyers can schedule a self-tour and receive a text with a code to unlock the property's door, tour, then buy from anywhere, anytime, with or without an agent or broker. There is a well-documented surging preference of younger demographics like Gen Y, Gen Z and Millennials for digital end-to-end customer journeys [18-22]. There is further a surging uptake of products and services where the size and value of the uptake can be determined by consumers. In the music industry as example, instead of buying the full record of one artist, consumers can buy only one track of their preference. How can retailers and manufacturers give more control over quality, size, pricing, delivery, intermediary, services, augmented product, alternative functionalities and product extensions? How can new inventions include new processes to ensure more control over and influence by potential users and other influencers of the customer journey?

\section{Manufacturers' \& Retailer-facing Strategies: Stakeholder Orientation}

\section{Creativity loves constraints}

The myth that creativity thrives in times of no stress has been thoroughly busted during the C19 lockdown. (Even my aged mother watches memes and YouTube videos making fun of politicians and humorous responses to the pandemic!). In an increasingly virtual and remote world, industries and services not traditionally on the digital circuit are finding ways to connect with and serve customers using tech-based solutions like live-streaming and mixed reality. On the housing front, DIY projects have increased hand over fist and in tertiary education MOOCS and virtual teaching assistants are taking a strong foothold. Google's VP of Product Development [9] reports: "People think of creativity as this sort of unbridled thing, but engineers thrive on constraints. They love to think their way out of that little box: 'We know you said it was impossible, but we're going to do this, this, and that to get us there."' Innovators and retailers will do well to regard every employee, every member of staff and every customer as a co-creator - willing and able to contribute new ideas and find workable solutions to new and old problems.

An unexpected surprise to tertiary education institutions was how well senior staff, set in their well-trodden ways, took to new ways of delivering training through technology-based channels. Within a week of lockdown, traditional in-person educators revised learning content, delivery methods and assessments to allow for synchronized and unsynchronized online learning and feedback. For in-home products IKEA collaborates with Space10 on to explore potential applications of visualization technologies to find creative solutions to home design challenges (e.g. using a virtual inflatable elephant to measure the height of your hallway's ceilings). In a tough and stressful time, when resources are scarce and time is of the essence, is it possible to leverage the tactical knowledge and creative intelligence of staff, customers and other stakeholders to find new or improved ways to problem-solve for current and potential customers? Perhaps both a good marketing and resource capabilities strategy is to trust a wider range (than solely product engineers) with innovation?

\section{Virtual bridge building}

To bridge Moore's adoption chasm [3,11], manufacturers and retailers can build a network of alliances to lead reluctant consumers to a safe, streamlined end-to-end buying decision process by using innovative interfaces. These interfaces range from artificial intelligence (AI) technologies or expert intermediaries who liaise with potential buyers, decision-makers or end-users on behalf of manufacturers and retailers and vice versa. This virtual bridge building between what is (current problems) and what could be (desired future), should experts from a variety of disciplines and useful (to consumers) allies to participate and contribute solutions. ATMOS $^{\mathrm{TM}}$ [12] for instance, connects home buyers to builders by centralizing all aspects of the building process in one platform- 
even offering a concierge service to help communicate with experts as needed throughout.

To achieve these, staff in all walks of the business should be allowed to interface with consumers, but also with a range of suppliers, sales channels and users. Concerted efforts should aim at extracting tacit knowledge and networks should be pursued and actively considered for enhanced solutions. In the education industry, scholars and educators are actively nudged by various procedures and incentives to "stand on the shoulders of giants who went before". Practitioners will do well to allow staff time to experience their products and the problems consumers might face, build intelligence and find giants on whom to stand. Manufacturers pursuing cross pollination and bridges between a host of allies will survive and thrive.

\section{Information load and reload}

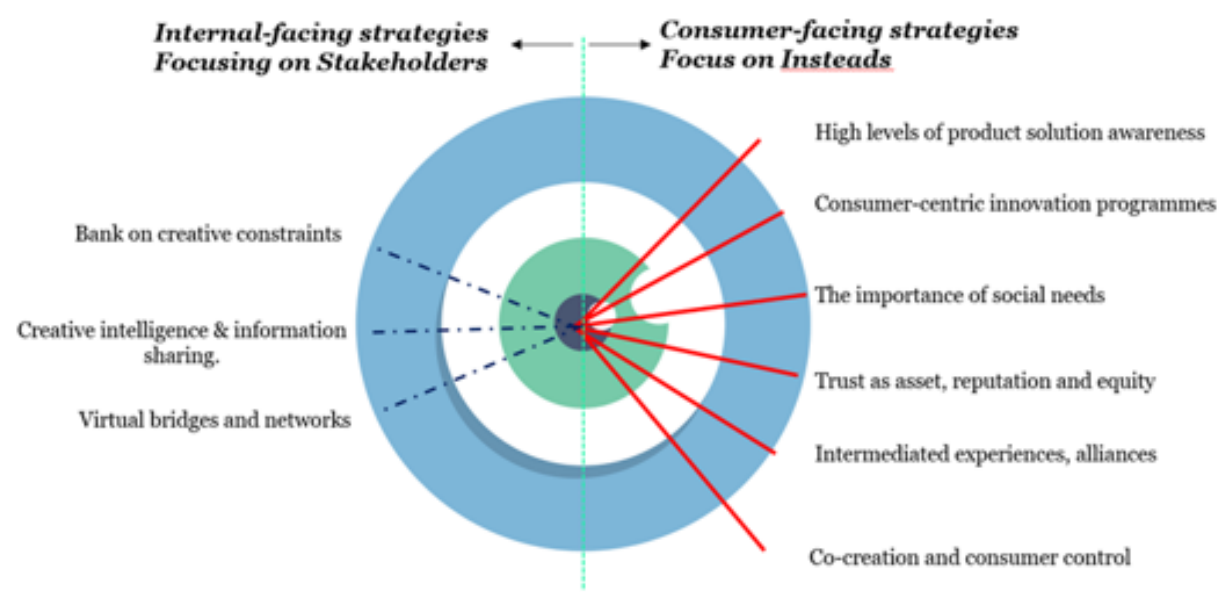

Figure 3: Crisis-riven accelerated technology adoption (CATA) strategies.

In order to achieve the collaboration and creative contributions regarding networks, alliances and solutions, stakeholders (including staff and consumers) need creative intelligence and relevant information. Google's VP of Products, Marissa Mayers offers this advice: "Share as much information as you can... employees have insight into what's happening with the business and what's important"... "If you're wondering, 'Who's working on maps?' you can find out. It allows us to share what we know across the whole company, and it reduces duplication." By loading and reloading up-to-date information, marketplace intelligence and consumer feedback, manufacturers and retailers can consciously equip stakeholders with the relevant knowledge to be valuable allies in the technology adoption cycle and over all stages of the customer journey. Thereby assisting both the firm and end-users to find more valuable solutions to problems, leading to faster technology adoption and diffusion cycles (Figure 3).

\section{In Summary}

Crisis-period consumption is basic needs-driven. The arrival of a cohort of needs-driven consumers (Insteads) during the current global health crisis pushes manufacturers and retailers further in the direction of meeting as many needs (over the entire spectrum of Maslow's needs hierarchy [23-25]) as possible via strategies both internal and consumer-facing. This framework identifies where firms can focus to bridge Moore's chasm and accelerate adoption of technological advancements considering nine strategic guides with a goal of designing ever more innovative solutions to meet consumer needs. Further, the CATA model can assist manufacturers and retailers to design strategies and tactics to artificially improve or accelerate the adoption of inventions and innovations by the majority of consumers, before competitors achieve a foothold or can enter the marketplace with their own alternatives/imitations and substitutes, allowing first mover advantage for a longer time or a higher share of market.

This paper proposes that crisis-driven accelerated technology adoption (CATA) merits future research and strategic adjustments in the six consumer strategies and three corporate strategies highlighted by this study. Future empirical research to investigate the antecedent conditions for accelerated uptake; the impact of Insteads on the Bass cycle and market size; various marketing, production and distribution strategies to optimize or simulate contextual opportunities should be investigated.

\section{Acknowledgement}

None.

\section{Conflict of Interest}

None.

\section{References}

1. World Health Organization. (2020) WHO Corona Virus (COVID-19) Disease Dashboard. 
2. Bass FM (1969) A new product growth for model consumer durables. Management Science 15(5): 215-227.

3. Norton JA, Bass FM (1987) A Diffusion Theory Model of Adoption and Substitution for Successive Generations of High-Technology Products. Management Science 33(9): 1069-1086.

4. Rogers E (1983) Diffusion of innovations (3/e). The Free Press, New York, NY, USA.

5. McGrath M (2019) The Pace of Technology Adoption is Speeding Up. Harvard Business Review.

6. Zoom (2020) News Release and Annual report.

7. Brown T (2020) Tim Brown of Allbirds Shares his Sneaker Secrets.

8. Konrad A (2017) How Zoom CEO Eric Yuan Turned Frustration into A \$1B Valuation In Six Years.

9. (2020) Zoom Video Communications Reports Fourth Quarter and Fiscal Year 2020 Financial Results.

10. Salter C (2009) Marissa Mayers' Nine principles of innovation.

11. Janney JE (1941) Fad and fashion leadership among undergraduate women. The Journal of Abnormal and Social Psychology 36(2): 275.

12. Moore JG (2015) Fashion Fads Through American History: Fitting Clothes into Context: Fitting Clothes into Context. ABC-CLIO.

13. Zillow (2020) Press Release: Home Shoppers are Trending Toward Buying Sight-Unseen, Selling Virtually.

14. Maurer F, Melnik G (2007) Agile methods: Crossing the chasm. In 29th International Conference on Software Engineering (ICSE'07 Companion) IEEE: 176-177.

15. Lelarge M (2008) Diffusion of innovations on random networks: Understanding the chasm. In International Workshop on Internet and Network Economics, Springer, Berlin, Heidelberg, pp. 178-185.
16. Moore G (1995) Crossing the chasm. Harper Business, New York, NY, USA

17. Mudambi SM, Schuff D (2010) Research note: What makes a helpful online review? A study of customer reviews on Amazon. com. MIS quarterly, 185-200.

18. Camacho-Otero J, Boks C, Pettersen IN (2019) User acceptance and adoption of circular offerings in the fashion sector: Insights from usergenerated online reviews. Journal of Cleaner Production 231: 928-939.

19. Lissitsa S, Kol O (2016) Generation X vs. Generation Y-A decade of online shopping. Journal of Retailing and Consumer Services 31: 304-312.

20. Bauckhage C, Kersting K (2014) Strong Regularities in Growth and Decline of Popularity of Social Media Services. arXiv:1406.6529.

21. Lim YJ, Osman A, Salahuddin SN, Romle AR, Abdullah S (2016) Factors influencing online shopping behavior: the mediating role of purchase intention. Procedia Economics and Finance 35(5): 401-410.

22. Swarnakar P, Kumar A, Kumar S (2016) Why generation Y prefers online shopping: a study of young customers of India. International Journal of Business Forecasting and Marketing Intelligence 2(3): 215-232.

23. Kautish P, Rai SK (2019) Fashion portals and Indian consumers: an exploratory study on online apparel retail marketing. International Journal of Electronic Marketing and Retailing 10(3): 309-331.

24. McLeod S (2007) Maslow's hierarchy of needs. Simply psychology 1: 1-8.

25. Singh V, Holmström J (2015) Needs and technology adoption: observation from BIM experience. Engineering, construction and architectural management. 